\title{
Subcellular Architecture of the xyl Gene Expression Flow of the TOL Catabolic Plasmid of Pseudomonas putida mt-2
}

\author{
Juhyun Kim, ${ }^{\text {a* }}$ Angel Goñi-Moreno, ${ }^{\text {b,c }}$ (D) Víctor de Lorenzo ${ }^{a}$ \\ aSystems Biology Department, Centro Nacional de Biotecnología-CSIC, Campus de Cantoblanco, Madrid, Spain \\ bCentro de Biotecnología y Genómica de Plantas (CBGP, UPM-INIA), Universidad Politécnica de Madrid (UPM), Instituto Nacional de Investigación y Tecnología Agraria y \\ Alimentaria (INIA), Campus de Montegancedo-UPM, Pozuelo de Alarcón, Madrid, Spain \\ cSchool of Computing, Newcastle University, Newcastle Upon Tyne, United Kingdom
}

ABSTRACT Despite intensive research on the biochemical and regulatory features of the archetypal catabolic TOL system borne by pWW0 of Pseudomonas putida strain $\mathrm{mt}-2$, the physical arrangement and tridimensional logic of the $x y l$ gene expression flow remains unknown. In this work, the spatial distribution of specific $x y l$ mRNAs with respect to the host nucleoid, the TOL plasmid, and the ribosomal pool has been investigated. In situ hybridization of target transcripts with fluorescent oligonucleotide probes revealed that $x y l$ mRNAs cluster in discrete foci, adjacent but clearly separated from the TOL plasmid and the cell nucleoid. Also, they colocalize with ribosome-rich domains of the intracellular milieu. This arrangement was maintained even when the $x y l$ genes were artificially relocated to different chromosomal locations. The same held true when genes were expressed through a heterologous T7 polymerase-based system, which likewise led to mRNA foci outside the DNA. In contrast, rifampin treatment, known to ease crowding, blurred the confinement of $x y l$ transcripts. This suggested that $x y l$ mRNAs exit from their initiation sites to move to ribosome-rich points for translation-rather than being translated coupled to transcription. Moreover, the results suggest the distinct subcellular motion of $x y l$ mRNAs results from both innate properties of the sequences and the physical forces that keep the ribosomal pool away from the nucleoid in P. putida. This scenario is discussed within the background of current knowledge on the three-dimensional organization of the gene expression flow in other bacteria and the environmental lifestyle of this soil microorganism.

IMPORTANCE The transfer of information between DNA, RNA, and proteins in a bacterium is often compared to the decoding of a piece of software in a computer. However, the tridimensional layout and the relational logic of the cognate biological hardware, i.e., the nucleoid, the RNA polymerase, and the ribosomes, are habitually taken for granted. In this work, we inspected the localization and fate of the transcripts that stem from the archetypal biodegradative plasmid pWWO of soil bacterium Pseudomonas putida strain KT2440 through the nonhomogeneous milieu of the bacterial cytoplasm. The results expose that-similarly to computers-the material components that enable the expression flow are well separated physically and they decipher the sequences through a distinct tridimensional arrangement with no indication of transcription/translation coupling. We argue that the resulting subcellular architecture enters an extra regulatory layer that obeys a species-specific positional code and accompanies the environmental lifestyle of this bacterium.

KEYWORDS Pseudomonas putida, xyIUW, xyIX, mRNA localization, specific DNA locus, TOL plasmid, biodegradation, $m$-xylene, mRNA, nucleoid, stress adaptation,

transcriptional regulation, translational control
Citation Kim J, Goñi-Moreno A, de Lorenzo V. 2021. Subcellular architecture of the $x y /$ gene expression flow of the TOL catabolic plasmid of Pseudomonas putida mt-2. mBio 12:e03685-20. https://doi.org/10.1128/mBio.03685-20.

Editor Caroline S. Harwood, University of Washington

Copyright $\odot 2021$ Kim et al. This is an openaccess article distributed under the terms of the Creative Commons Attribution 4.0 International license.

Address correspondence to Víctor de Lorenzo, vdlorenzo@cnb.csic.es.

* Present address: Juhyun Kim, Department of Chemical Engineering, Imperial College London, London, United Kingdom.

This article is a direct contribution from Victor de Lorenzo, a Fellow of the American Academy of Microbiology, who arranged for and secured reviews by Juan Ramos, Consejo Superior de Investigaciones Científicas -EEZ, and Orna Amster-Choder, The Hebrew University Faculty of Medicine, Jerusalem, Israel.

Received 8 January 2021

Accepted 11 January 2021

Published 23 February 2021 
- he TOL system, encoded by plasmid pWW0 of Pseudomonas putida mt-2, is to this date the most thoroughly studied example of a biodegradative system in soil microorganisms. The primary function of this catabolic device is enabling carrier bacteria to grow on toluene, $m$-xylene, $p$-xylene, and other related aromatics through a set of enzymes encoded by upper and lower plasmid-borne operons (Fig. 1A; 1-3). While catabolic traits of this sort are not uncommon in many other environmental isolates, what makes the TOL system special is the extraordinary regulatory intricacy that controls expression of the $x y l$ genes and their high-level interplay with the host's physiological regulons. The many mechanisms unveiled over the years in this respect seem to include nearly every device known in the prokaryotic world for controlling the flow of gene expression (4-6). This state of affairs has made the TOL plasmid and its bearer $(P$. putida KT2440) a beneficiary of the suite of conceptual and material tools of contemporary systems and synthetic biology $(7,8)$. In particular, the wealth of experimental data on expression of the $x y l$ genes has enabled the understanding of the cognate regulatory network as a complex device that processes inputs into outputs following a layer of logic gates implemented with promoters, transcriptional factors, and small RNAs (sRNAs; 9, 10). It could thus be argued that we know at this point much about the genetically encoded "software" of the system and the relational logic that rules its performance. In contrast, we know virtually nothing of the physical arrangement of the "hardware" that sustains the same process. In particular, the gross spatial disposition of the molecular actors that execute the transfer of information from the xyl genes to production of catabolic enzymes is unknown.

The same types of questions have been tackled in other prokaryotic systems. There seem to be at least two different patterns of transcript localization. In one scenario, the mRNA remains close to the site of transcription. This is the case of the mRNAs of groESL and creS of Caulobacter crescentus and lacZ of Escherichia coli, which appear to remain in the vicinity of the corresponding genomic DNA loci from where they are transcribed (11). This suggests that for mRNAs to be translated they need to be associated with ribosomes while being produced (as the prevailing view of generalized transcription-translation coupling would imply) or shortly after their creation by RNA polymerase (RNAP; 11, 12). An alternative scenario involves migration of mRNAs to specific spots of the cytoplasm for translation close to the site(s) where the gene products are needed. While this setting argues against generalized transcription/coupling translation, there is solid evidence of its occurrence, e.g., the bgIGFB operon, whose products were located in subcellular localizations where cognate proteins were expected to function (13). This example may not be anecdotal, as transcriptome-wide scale studies of mRNA localization in $E$. coli revealed that a large share of transcripts were found in cell domains (e.g., membranes, cytoplasm, poles) that coincided with the functions of the corresponding proteome $(14,15)$. Furthermore, the mRNA of archetypal membrane proteins LacY and TetA are distinctively close to the cell envelope $(16,17)$. In other instances, a signal-recognition particle (SRP) is involved in the movement of mRNAs to the membrane, as translation of some mRNAs encoding inner membrane proteins produces a signal peptide that recruits such SRP and the complex leads the transcript to its intracellular address $(15,16,18)$. Finally, Rho-dependent transcription termination in Bacillus subtilis is somewhat weak, and "runaway," i.e., untranslated, mRNAs are abundant (19). In sum, the fate of each transcript seems to be both gene (i.e., sequence)-dependent and species-dependent.

In this work, we have inspected the localization of mRNAs initiated in the catabolic promoters of the TOL plasmid pWWO of $P$. putida mt-2. The starting point for tackling the issue is the earlier observation that RNA polymerase (RNAP) of $P$. putida fully colocalizes with the chromosomal DNA of the nucleoid while being entirely apart from the bulk of the ribosomal pool (20). This observation suggested that, rather than being coupled to translation $a b$ initio, many (if not most) of the mRNAs initiated at chromosomal promoters need to move to ribosome-rich, nucleoid-free domains of the intracellular space for translation. Note that in the case of the $x y /$ promoters, transcription 
A

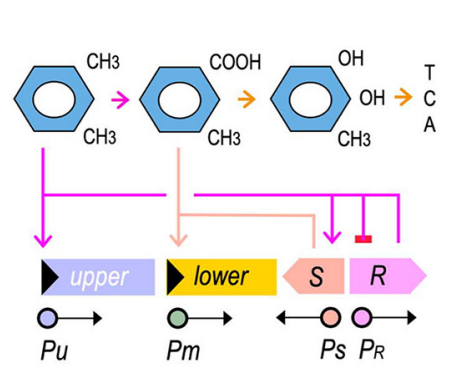

C
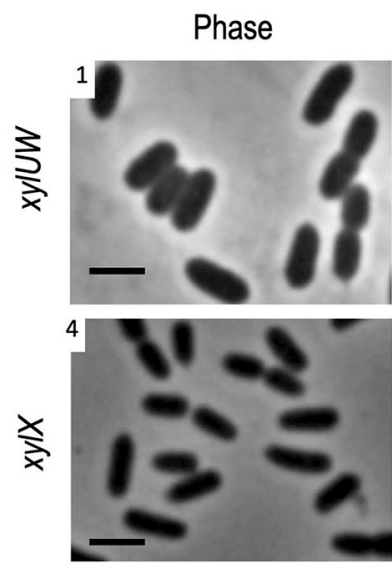

B

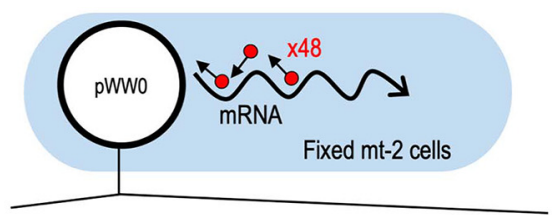

mRNAFISH

to detect

$x y l$ transcripts

FIG 1 Interplay between metabolic and regulatory components of the TOL network and visualization of transcripts from either the upper or the lower operons of the system. (A) In the presence of $m$-xylene, XylR (expressed from $P_{R}$ ) activates both the $P u$ promoter (which transcribes the upper pathway operon) and the $P S$ promoter, stimulating expression of the xylS gene. Also, XyIR expression is negatively auto-regulated. In turn, the XylS protein induces the lower operon by activating the $\mathrm{Pm}$ promoter with its effector 3-methylbenzoate $(3 \mathrm{MBz})$, an intermediate metabolite of $m$-xylene biodegradation. (B) Scheme of the fluorescent in situ hybridization (FISH) approach adopted to visualize mRNAs of the TOL operons of plasmid pWW0. For this experiment, $P$. putida $\mathrm{mt}-2$ strain was grown to mid-exponential phase in succinate-supplemented minimal medium and then exposed for $2 \mathrm{~h}$ to saturating vapors of $m$-xylene to activate transcription of the $x y l$ genes. After fixation of samples with formaldehyde, the FISH experiment was performed with either the upper (xylUW) or the lower pathway $(x y I X)$ probe set, which included a mix of 48 synthetic oligonucleotides tagged with a red fluorophore and complementary to each mRNA sequence. (C) FISH on xyIUW and $x y I X$ transcripts, as indicated. Phase contrast (panels 1 and 4); mRNA-red signals (panels 2 and 5); and composite images (panels 3 and 6) are shown. Scale bar, $2.5 \mu \mathrm{m}$.

initiates in an extrachromosomal element, and therefore the three-dimensional (3-D) itinerary of the corresponding mRNAs could be different. As shown below, by merging genetic analyses with in situ RNA-FISH (fluorescence in situ hybridization) and DNAFISH technology, we could faithfully locate the relative positions of the nucleoid DNA, the pWW0 plasmid, the $x y l$ transcripts, and the ribosomes to predict the motion of cognate mRNAs through the cell interior. The results exposed an unexpected degree of physical partitioning among the material actuators of the gene expression flow that may help $P$. putida to deal with its typical environmental settings.

\section{RESULTS AND DISCUSSION}

mRNAs of catabolic genes expressed from the TOL plasmid are spatially organized. To visualize specific mRNAs of $P$. putida mt-2 stemming from the TOL operons of plasmid pWW0, we adopted an RNA-FISH approach (Fig. 1B). To this end, the strain was cultured in M9 minimal medium with succinate as the sole carbon source until the cells reached exponential phase. At this point, the cultures were exposed (or not) to saturating vapors of $m$-xylene to induce transcription of the catabolic xyl genes. After $2 \mathrm{~h}$, samples were collected and fixed with formaldehyde for hybridization with specific probes as described in the Materials and Methods. For this, 
two sets of 48 CAL Fluor Red 610-tagged fluorescent oligonucleotides (20 nt long; Table S2 in the supplemental material) were synthesized that covered, respectively, the leading 1,418 bp of the upper TOL operon transcript, spanning the whole of $x y / U$ and part of $x y / W$ (encoding benzyl alcohol dehydrogenase), and the front segment of the TOL lower operon, encompassing 1,203 bp of the $x y / X$ gene (alpha subunit of toluate 1,2-dioxygenase). After hybridization with these oligonucleotide sets, the samples were washed and red signals inspected with fluorescence microscopy.

As shown in Fig. 1C, distinct, discrete fluorescent foci were clearly noticed under the microscope ( 1 to 2 per cell) from the cultures subject to $m$-xylene exposure upon in situ hybridization with upper or lower pathway-specific oligonucleotides. In contrast, no signals were detected in bacteria grown in M9-succinate without aromatic effector (Fig. S1A). These observations confirmed that the designed probe sets and the methodology were working as expected, as there were no signals that could be attributed to hybridization with DNA. Therefore, the foci appeared to represent upper or lower $x y l$ transcripts. To further verify the experimental approach, cells were treated with either toluene (an alternative TOL substrate) or o-xylene (a gratuitous inducer of the upper pathway and downstream activator of the lower pathway (21, 22; Fig. S1B). Under these conditions, fluorescent foci for both the $x y l U W$ and the $x y I X$ transcripts were observed as expected. In contrast, cells treated with benzoate or 3-methyl benzoate (substrates of the lower pathway) produced signals for $x y I X$ mRNA only (Fig. S1B). Appearance of the fluorescent signals matched the known regulatory network that rules the interplay between the substrates, regulators, and catabolic operons of the TOL system (Fig. 1A). We could thus safely consider that the foci inside cells shown in Fig. $1 C$ were the result of the bona fide hybridization of the fluorescent probes to specific mRNA of xylUW or xylX. Closer inspection of the images revealed that no red output ever appeared dispersed throughout the cell, but always as discrete foci (Fig. 1B). Yet, their position in respect to the cell shape varied among cells, with signals located near the center, the poles, the contour, or the septum of the cells (Fig. 1C). We thus set out to characterize this asymmetrical localization of the $x y l$ transcripts with respect to the nucleoid occupation and to the TOL plasmid, as explained below.

xyl mRNAs occupy subcellular nucleoid-free regions. In order to identify the relative localization of the $x y /$ transcripts with respect to the nucleoid following hybridization with the fluorescent probes, as described above, the bacterial genome was stained with 4', 6-diamidino-2-phenylindole (DAPI) in cells exposed to $m$-xylene. The results of this procedure with the upper and lower pathway TOL probes ( $x y / U W$ and $x y I X)$, respectively, are shown in Fig. 2. Images were processed and signals analyzed with the CellShape software. For interpreting these results, note that (i) previous work showed that the DNA of the nucleoid overlaps spatially with the P. putida RNAP (20) and (ii) DAPI binds both chromosomal and plasmid DNA. Inspection of the cells under the microscope (Fig. $2 \mathrm{~A}$ ) revealed that signals stemming from $x y / U W$ or $x y / X$ transcripts (red foci) were located in sites inside cells with a low DAPI signal, i.e., in the nucleoidfree regions. In order to quantity the phenomenon, $>100$ pictures of individual DAPIstained and fluorescent oligonucleotide-hybridized cells were separately recorded with the blue and red channels of the fluorescence microscope and automatically inspected with the CellShape image analysis tool ((23); Fig. 2B). The outcome of this analysis is shown in Fig. 2 C. Very few red foci $(<1 \%)$ overlapped with the densest DAPI signals, and as little as $15 \%$ of fluorescent spots from either xylUW or xyIX RNA were detected at the peripheral regions of genomic DNA. Instead, the vast majority of the remaining foci were situated away from the blue signal (Fig. 2C). It thus appeared that the bulk of TOL transcripts were located within subcellular regions with no or little overlap the DNA signal and therefore virtually devoid of RNAP (20). This suggests that, once formed, $x y /$ mRNAs could migrate for translation to a site different from the place where transcription is initiated. Note that the pathway substrate ( $m$-xylene) dissolves in the cell membrane (24). Moreover, the xylM product (hydroxylase component of the leading pathway enzyme xylene monooxygenase) is located in the membrane (25). It is 
A
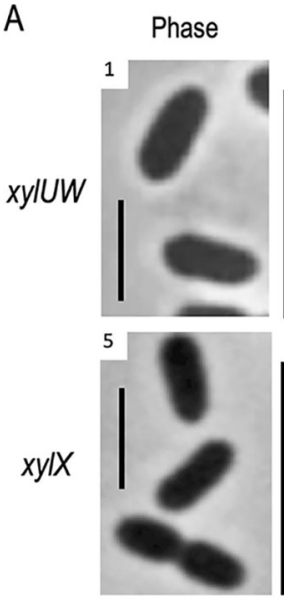

FISH
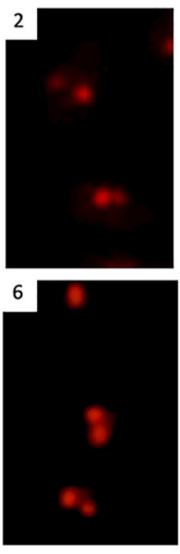

DAPI
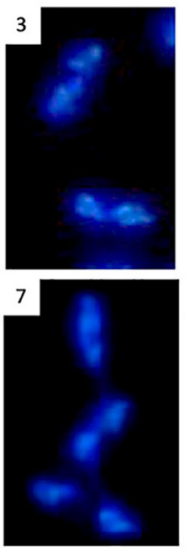
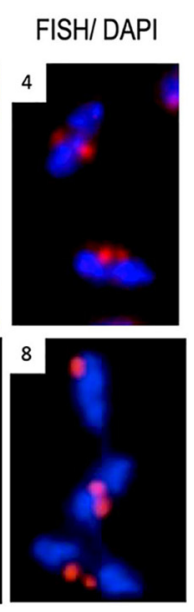

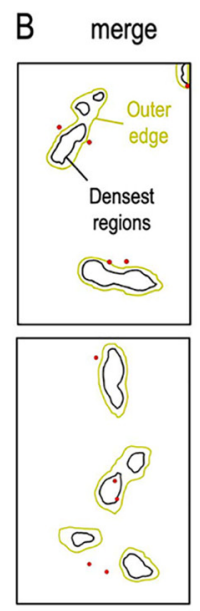

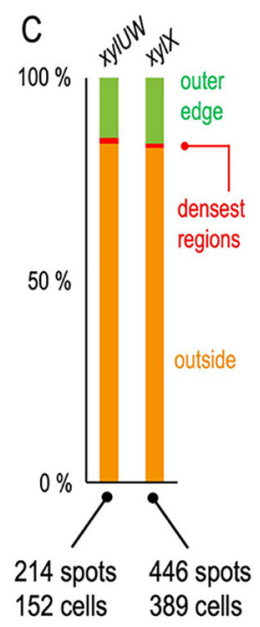

FIG 2 Spatial distribution of TOL catabolic transcripts in respect to the nucleoid of $P$. putida cells. (A) mRNA signals of xyIUW and $x y I X$ were obtained with FISH (panels 2 and 6), while the nucleoid was stained with DAPI (panels 3 and 7). The mRNA-red and the DNA-blue channels were merged (panels 4 and 8) to identify relative positions of the $x y l$ transcripts with respect to one another. Phase-contrast images (panels 1 and 5) of the same cells are also shown. Scale bar, $2.5 \mu \mathrm{m}$. (B) Application of the image analysis tool CellShape on exemplary cells enabled identification of the contours of each fluorescent signal. The densest regions of the DAPI-stained DNA are delimited with black lines, while relatively less concentrated DNA sections are bounded by yellow lines. (C) Abundance of $x y l$ mRNAs with respect to the nucleoid. xyIUW (214 spots from 152 cells) or xyIX signals (446 spots from 389 cells) were quantified according to their coincidence with the DNA signal.

not uncommon that genomic sites encoding envelope-associated proteins are transcribed coupled and cotranslationally inserted to the membrane through a so-called "transertion" mechanism (16). In the case of the TOL transcripts, it appeared instead that movement away from the DNA begins after transcription has terminated and the mRNA has disengaged from the nucleoid. To clarify this, we examined the relative position of the $x y /$ mRNA with respect to their actual origin inside the cells (i.e., the TOL plasmid), as described below.

$x y l$ transcripts map near but do not overlay the TOL plasmid. Identifying the subcellular localization of the TOL plasmid within the whole of the DAPI-stained DNA of the $P$. putida nucleoid required first tagging pWW0 with a different fluorescent label. A 9,679-bp DNA sequence, including an array of tandemly repeated tetO operators for the TetR repressor (26), was inserted into a site in the plasmid between and close to the upper and lower operons, i.e., by ORF105 of the current annotation (27; Fig. $\mathrm{S} 2 \mathrm{~A})$. The corresponding sequences could then be exposed through FISH with a special type of 6-carboxyfluorescein (6-FAM)-labeled 18-nt oligonucleotides. These encoded the tetO operator and bore a distinctive chemical configuration (so called locked nucleic acid [LNA] structure) that increases specificity for target DNA (11; Fig. S2A). Samples were thus first hybridized with $x y l$-specific (red fluorescence) and pWW0-specific (green fluorescence) probes and then stained with DAPI. As a result of this procedure, both red, green, and blue fluorescent signals could be mapped in cells exposed to $m$-xylene, corresponding to $x y I U W$ or $x y I X$ mRNA, plasmid, and nucleoid, respectively (Fig. $3 B$ to $D$ and Fig. 4B to D). In contrast, cells grown without the aromatic compound lacked the red signal altogether (Fig. S3A).

The control images (panels 1 and 2 of Fig. 3B to D and Fig. 4B to D; Fig. S3) show individual bacteria hosting discrete green spots in cells bearing the TOL plasmid variant tagged with the tetO array. In contrast, no defined green foci were observed in cells with the intact TOL plasmid devoid of the same array (Fig. S2B). This verified that the tetO probe hybridized specifically to the tagged plasmid without significantly interacting with any other DNA of the cells. Further inspection of the pictures indicated that the green signals appeared only once or twice in every cell (in the last case in a symmetrical fashion; Fig. S3). Such a subcellular distribution of the plasmid has been 
A

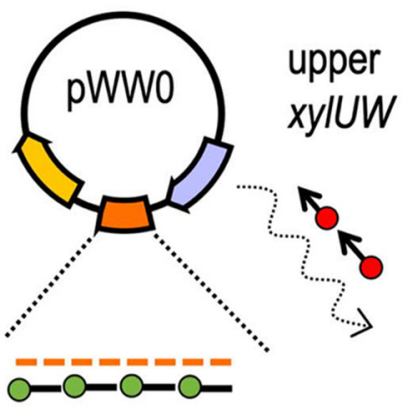

tetO array (tetO x 140)

C

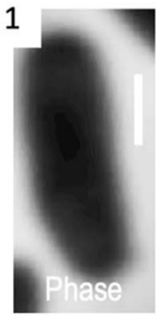

5

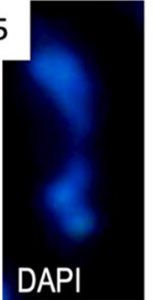

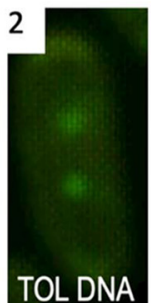

6

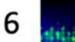

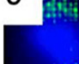

语

학

DAPI/TOL
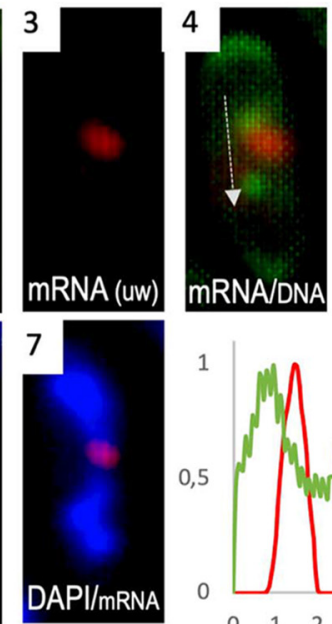
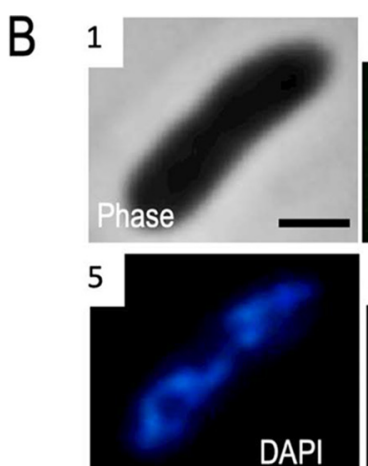

DAPI
2
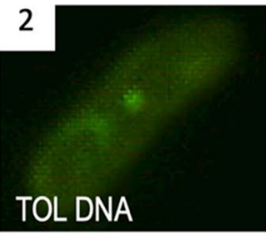

6

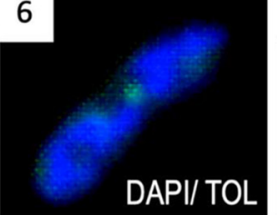

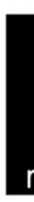

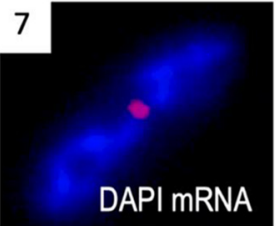

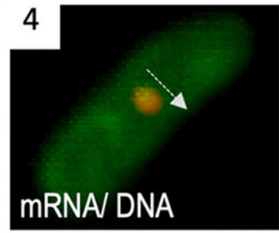

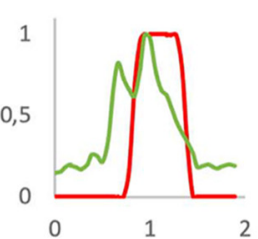

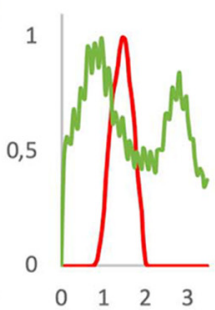

$D_{1}$
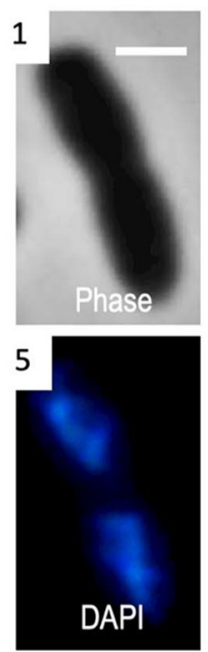

2
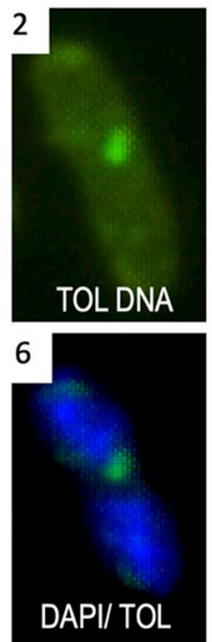

3
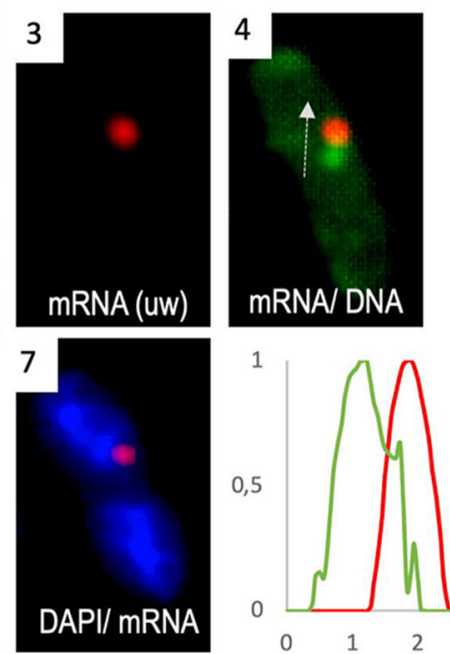

FIG 3 Covisualization of the xyIUW transcript and the pWWO plasmid. (A) Sequentially combined RNA-FISH and DNA-FISH was carried out to visualize both the $x y / U W$ mRNA and the pWW0 plasmid in P. putida cells. Bacteria carried a variant of the plasmid inserted with an array of tetO operators in a permissive locus between the upper and lower operons. A green fluorophore-tagged tetO probe was used for hybridization in the DNA-FISH procedure. (B to D) $P$. putida mt-2 (pTOL-tetO) strain was exposed to $m$-xylene for $2 \mathrm{~h}$ and processed for FISH. A few representative cells are shown, exposing dynamic localization patterns of the mRNA relative to the DNA. Pictures show phase contrast of cells (panels 1), plasmid DNA (green, panels 2), xylUW mRNA (red, panels 3), and the nucleoid (blue, panels 5), respectively. Composite images include mRNA/plasmid DNA (panels 4), plasmid DNA/nucleoid (panels 6), and mRNA/nucleoid (panels 7). Relative intensities of mRNA-red and plasmid-green signals were measured and represented in plots in which the $y$ axis refers to relative fluorescence intensity and the $x$ axis indicates pixel distance projected on the arrow drawn in merged panels 4 . Scale bar, $1 \mu \mathrm{m}$. As an aside, the images in panels labeled 2 also show that the TOL plasmid exists as a low-copy replicon $(\sim 1$ molecule per cell of $P$. putida).

observed before (28) and plausibly reflects the plasmid partition system (29-31). Once the position of the TOL plasmid was determined, by filtering the images with the adequate color channels we could pinpoint the relative localization of pWW0, the nucleoid, and the TOL transcripts.

Fig. 3B to $D$ and Fig. 4B to $D$ show a few examples of cells processed and filtered to locate the $x y I U W$ (upper pathway) and the $x y I X$ mRNAs (lower pathway), respectively. Each of these images was not only visually inspected but the signals were also quantified with the CellShape software (23; Fig. S4). In general, the transcripts from either the upper or the lower TOL pathway behaved similarly. The first piece of information resulting from a detailed image analysis (panels 2 and 6 of Fig. $3 B$ to $D$ and Fig. $4 B$ to $D)$ is that the TOL plasmid could be found both in DAPI-intense regions and in the peripheral space of the cytoplasm with little or insignificant DAPI signal. This agrees with the pWW0 predicted segregation system; the presence of plasmid-encoded parA and parB indicates pWWO bears a type I partition mechanism (27) through which the plasmid can either detach or remain connected to the chromosome through a ParA-ATPnucleoid complex (30).

Inspection of colored spots merged within the contours of single cells exposed two predominant spatial arrangements of the different signals. In one case, red and green 
A

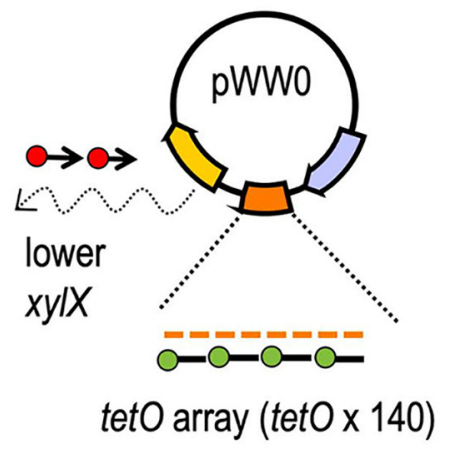

C
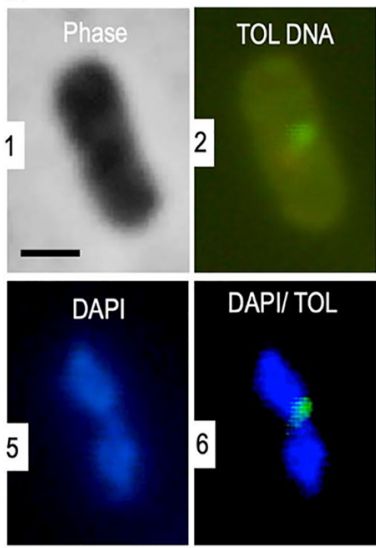
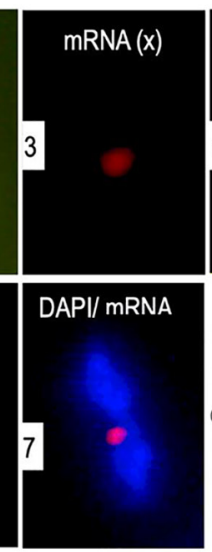

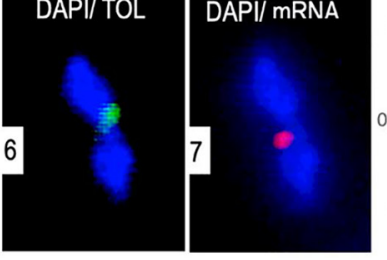

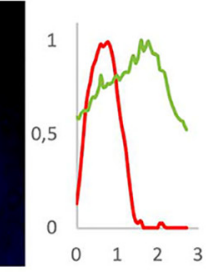

B
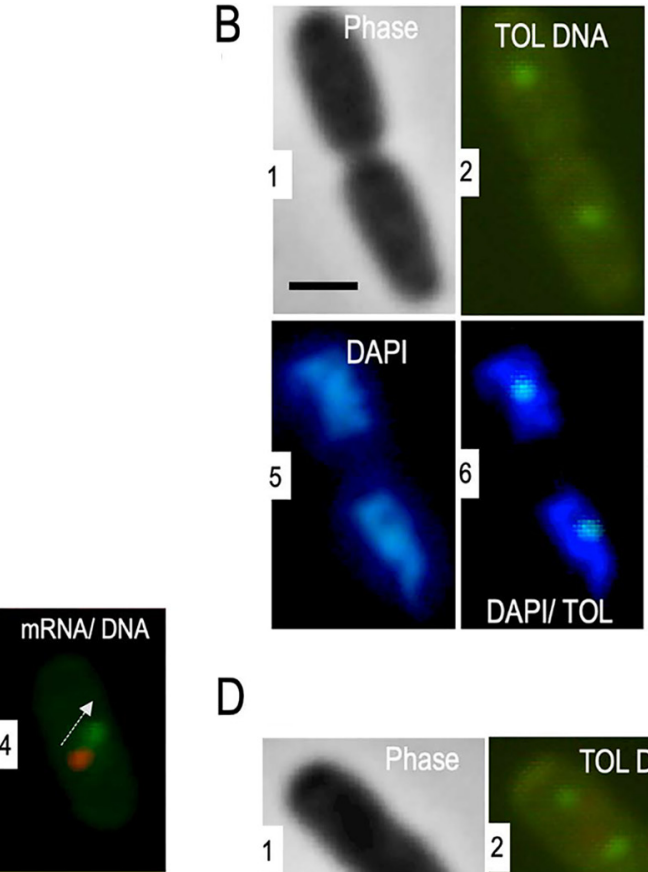

D

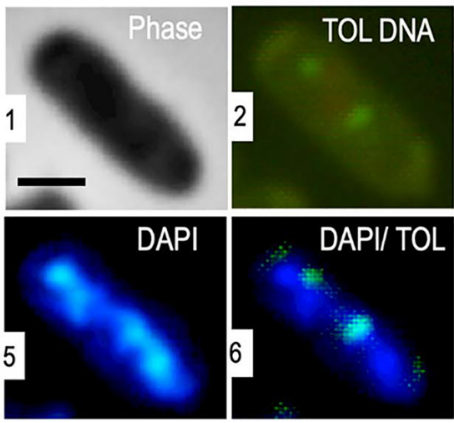

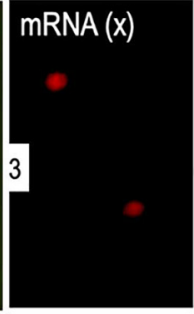
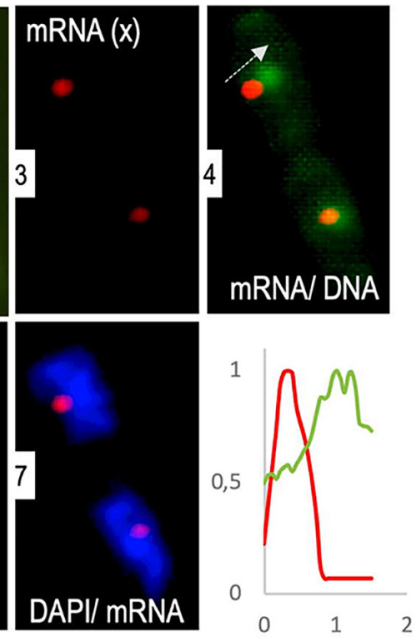

FIG 4 Dual labeling of the $x y I X$ mRNA and the pWWO plasmid. (A) The same approach was used as described in Fig. $3 A$, but red fluorophore-tagged $x y I X$ probes were used in this case for the combined RNA-FISH and DNA-FISH to visualize both the lower pathway transcripts and the TOL plasmid. (B to D) Cellular location of plasmid DNA versus $x y I X$ mRNA. Panel tags are the same as those of Fig. 3.

spots virtually colocalized (e.g., Fig. 3B), while in most others, the two signals were close to each other but clearly separated (Fig. 3C and D and Fig. 4B to D). It is likely that these two scenarios reflect different stages of transcription of $x y$ l genes. In an early stage, mRNA is necessarily tethered to its DNA template in the plasmid and therefore the gene and its transcript occupy the same spot. However, at a later stage, the $x y l$ mRNA could move away from the plasmid toward nucleoid-free ribosome-rich domains of the inside of the cell (20). Note that the sizes of the upper and lower TOL operons are $\sim 8 \mathrm{~Kb}$ and $11 \mathrm{~Kb}$, respectively, and, if linearly stretched, the $5^{\prime}$ ends of their full-length mRNAs could be found well away from the plasmid while still tethered to the template. However, it is known that the mRNA from the lower pathway is quite short-lived and starts being degraded before it is fully synthesized (32). Note also that mRNA tends to form secondary structures that shorten the distances between the $5^{\prime}$ and $3^{\prime}$ ends (33). On this basis, we argue that separation of red and green spots in the images shown in Fig. 3, Fig. 4, and Fig. S4 reflects an authentic migration of the TOL transcripts away from their DNA template. The next obvious question was whether this was the result of TOL genes being encoded in a type of plasmid that largely stays in the periphery of the nucleoid (see above). Alternatively, the unexpected localization of $x y l$ mRNAs could stem from intrinsic properties of the transcripts themselves. In order to distinguish between these possibilities, we introduced various types of perturbations into the system.

xyl transcripts move away from the nucleoid regardless of their replicon. Although the native physical location of the TOL genes is on plasmid pWW0, the same growth phenotype on aromatic compounds can be brought about when the upper 
A

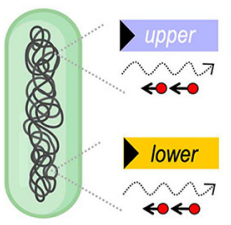

P. putida PaW140
B

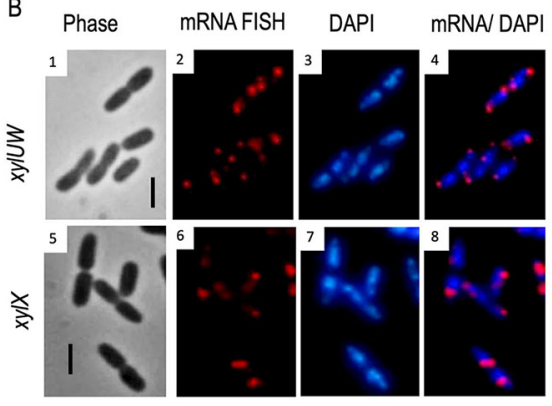

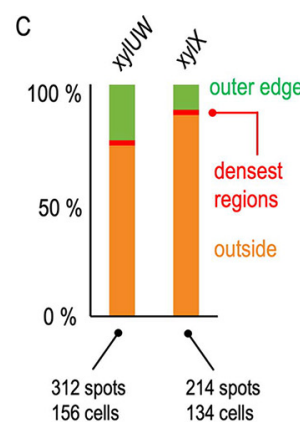

FIG 5 Effect of replicon type on localization of $x y /$ mRNAs. (A) The $P$. putida PaW140 strain, carrying the two operons of the TOL system inserted into the chromosome, was used to identify the distribution of $x y l$ mRNAs with the same methods used with the P. putida mt-2 strain above. (B) RNAFISH-enabled visualization of $x y I U W$ (panel 2) and $x y I X$ mRNA signals (panel 6). Cognate phasecontrast images (panels 1 and 5), the nucleoid (blue, panels 3 and 6), and merged pictures (panels 4 and 8) are shown. Scale bar, $2.5 \mu \mathrm{m}$. (C) Quantification of mRNA-red foci with respect to the nucleoid occupation. Note that the number of red spots per cell increased by $\sim 30 \%$ in the $P$. putida PaW 140 strain compared to P. putida mt-2 (Fig. 2C).

and the lower pathways are placed into the chromosome. This may happen either naturally (34) or by engineering the corresponding DNA segments into the genome of a heterologous host (35). We took advantage of this for exploring whether the position of the $x y /$ DNA template affects the spatial distribution of the transcribed RNAs. To this end, we used P. putida strain PaW140 (36), which carries both the upper and lower operons and their cognate regulators in its chromosome (Fig. 5A). The strain was grown and induced with $m$-xylene under identical conditions as before and cells fixed and hybridized with RNA probes to expose $x y l U W$ and $x y I X$ transcripts with respect to the bacterial nucleoid. The results in Fig. 5B show the number of foci per cell to increase by $\sim 30 \%$ in $P$. putida PaW140 compared to the lower numbers in the pWW0bearing $P$. putida $\mathrm{mt}-2$ strain (Fig. 2C), quite likely due to a higher transcriptional activity. This is not surprising, as the pedigree of strain $P$. putida PaW140 involved random chromosomal insertion of TOL genes and selection for the best growth on $m$-xylene, which plausibly favored insertions into regions of high transcriptional activity (37-39). Yet, when RNA-red signals were compared to those of the DAPI-stained nucleoid, most of them were observed away from the denser DNA regions. Specifically, $<3 \%$ of the red spots of either $x y l$ mRNAs overlapped the more compacted chromosome, while $74 \%$ of $x y I U W$ and $87 \%$ of $x y I X$ signals were enriched in the peripheral space of the cell (Fig. 5B and C). Preferential localization of $x y l$ mRNAs was thus maintained regardless of the replicon (plasmid versus chromosome) that bears the cognate genes. Moreover, the higher incidence of TOL mRNAs in the nucleoid-free subcellular regions corroborates that $x y /$ transcripts move away from their transcription site.

Exclusion of $x y l$ mRNAs from the nucleoid is independent of the transcriptional machinery. A second type of perturbation in the architecture of the $x y /$ gene expression flow involved complete replacement of the native $\sigma^{54}$-dependent $P u$ promoter of the upper operon of the pWW0 plasmid $(40,41$; Fig. $1 \mathrm{~A})$ by a heterologous expression T7 system. The replacement was engineered into the pWWO plasmid as explained in the Materials and Methods section and the resulting construct (pTOL-PuxT7) was then passed to strain P. putida KT2440.T7 (42), which expresses the T7 RNA polymerase through a genomic insertion of a lacla/P $/$ lac $-T 7 p o l$ cassette (Fig. 6A). As shown in Fig. S5A, the modified plasmid did not support $m$-xylene metabolism in cells without T7 RNAP because it did not transcribe the upper pathway. Due to the leakiness of the $P_{\text {lac }}{ }^{-}$ T7pol born in the $P$. putida chromosome, some red signals indicative of xylUW expression were detected in samples without isopropyl- $\beta$-D-thiogalactopyranoside (IPTG; Fig. $\mathrm{S} 5 \mathrm{C})$. Note also that there were RNA dots stemming from the lower pathway in the wild-type $P$. putida mt-2 host bearing the modified plasmid pTOL-PuxT7 (Fig. S5B). This is because $m$-xylene-activated XyIR caused overexpression of XylS, which in turn 
A

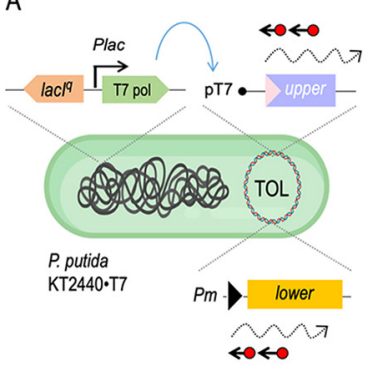

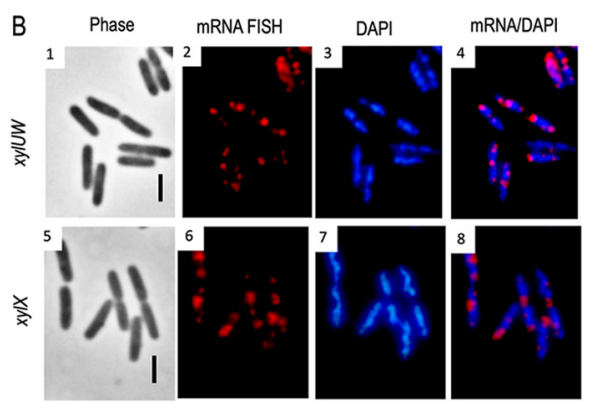

FIG 6 Localization of $x y l$ mRNAs transcribed with an orthogonal RNAP. (A) Schematic of RNA-FISH experiments with the modified plasmid pTOL-PuxT7 in P. putida strain KT2440.T7, which expresses T7 RNAP from a chromosomally inserted $/ a I^{9} / P l a c-T 7 p o l$ cassette. After $2 \mathrm{~h}$ of exposure of cells to $m$-xylene, $x y l$ transcripts were visualized with RNAFISH technology as before. (B) xylUW mRNA (panel 2); $x y I X$ mRNA (panel 6); DAPI-stained DNA (panels 3 and 7); merged pictures (panels 4 and 8); and phase contrast (panels 1 and 5). Scale bar, $2.5 \mu \mathrm{m}$. (C) Quantification of mRNAred and DAPI-blue signal overlap with subpixel precision ( $>100$ exemplary cells were considered for the colocalization analysis).

suffices to activate the Pm promoter even in the absence of any effector $(5,43,44)$. As a consequence, when pTOL-PuxT7 was placed in P. putida KT2440·T7, two things happened: (i) $P_{T 7}$ activation elicited formation of both xylUW transcripts (Fig. 6, panels 1 to 4) and $x y / X$ transcripts (Fig. 6, panels 5 to 8 ) in the complete absence of the aromatic inducers used before; and (ii) cells could grow on minimal medium with $m$-xylene as sole carbon source (Fig. S5A) due to the performance of both the upper and the lower TOL pathways. This made sense within the current model of regulation of the $x y l$ operons discussed above (Fig. 1A). But in contrast to the effect of the native effectors in the naturally occurring system, the surrogate control of the upper route by T7 polymerase originated a higher number of distinct foci per cell. While this reflected the strength of the $P_{T 7}$ promoter compared to $\mathrm{Pu}$ (which propagated into a more potent activity of the $P m$ promoter as well), it is noteworthy that the red signals always appeared focused (i.e., constrained within a subcellular domain) rather that diffused throughout the cytoplasm. Further, they again materialized mostly in the nucleoid-free regions. Automated quantification of signals detected with the red and blue channels in individual cells with pixel precision revealed that $91 \%$ of the xylUW and $98 \%$ of the $x y I X$ transcripts were excluded from the DAPI-stained field (Fig. 6C). Given that such transcripts originated in single promoters per bacterium and that nucleoid-free domains of $P$. putida cells are filled with ribosomes (20), it is possible that the images of Fig. 6 reflect the detachment of the transcripts from their promoters (whether $P_{T 7}$ for $x y l U W$ or $P m$ for $x y I X$ ) and their relocation elsewhere in the cytoplasm for translation.

In addition, one important piece of evidence embodied in these experiments is that formation of mRNA foci and apparent motion toward ribosome-rich subcellular sectors occurs regardless of whether the cognate RNAP can (host polymerase) or cannot (T7pol) couple transcription to translation. This rules out that the distinct foci of $x y / U W$ and $x y I X$ mRNAs shown throughout this work reflect the action of transcription/translation complexes (the so-called expressome $[45,46]$ ) on the nucleoid surface. Instead, it seems that the untranslated TOL transcripts move away from their promoters, plausibly toward other subcellular locations for translation. But, if that were the case, what physical forces prevent their diffusion throughout the cytoplasm?

Disruption of intracellular crowding enables xyl transcripts to diffuse throughout the cytoplasm. The data above support that $x y l$ mRNAs leave the proximity of the nucleoid toward the ribosome-enriched subcellular domains. Although a role for specific RNA-binding proteins cannot be ruled out as drivers of the process, a simpler explanation is that the corresponding sequences endow the $x y$ l transcripts with physical properties that cause them to be quickly discharged from the vicinity of the nucleoid, especially if the transcribed sequences are large. In fact, it seems that smaller RNAs 

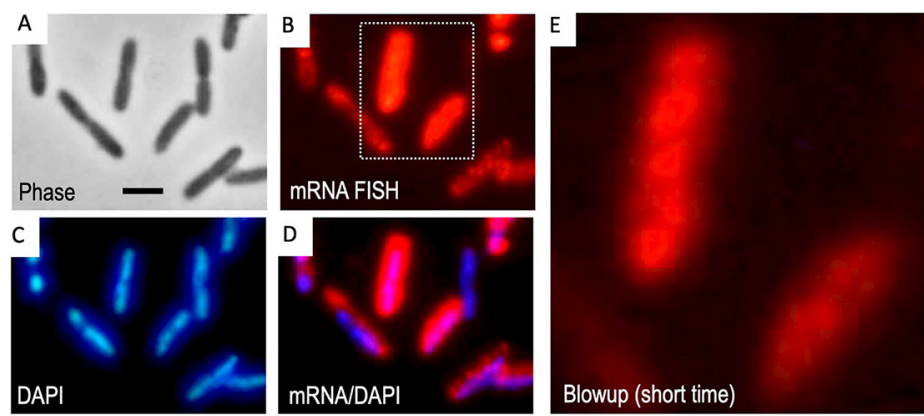

FIG 7 Effect of perturbing macromolecular crowding-by inhibiting bacterial transcription-on the spatial distribution of xylUW mRNA. P. putida KT2440-T7 (pTOL-PuxT7) cells were exposed for $2 \mathrm{~h}$ to $m$-xylene and rifampin $\left(200 \mu \mathrm{g} \mathrm{ml}^{-1}\right)$ and the intracellular location of xylUW mRNA was assessed with RNA-FISH as before. (A) Phase-contrast. (B) Red signals indicate fluorescently labeled oligonucleotides that hybridize to xylUW mRNA (note dispersion throughout the cell). (C) DAPI-staining. (D) Merged picture of mRNA-red and DAPI-blue channels. (E) Same image as panel B with a shorter exposure time. Scale bar, $2.5 \mu \mathrm{m}$.

appear uniformly distributed throughout the bacterial cell, while longer molecules typically display more limited dispersion (47). Large mRNAs can hardly colocalize with densely packed DNA regions due to straight physical forces, e.g., excluded volume effects $(48,49)$. As a consequence, the more crowded the bacterial cytoplasm, the less diffusion there is of cellular components and molecules, logically, in a size-dependent fashion $(50,51)$.

In order to test whether such a mutual exclusion between different intracellular domains accounted for the unusual behavior of the $x y l$ mRNAs, we treated P. putida KT2440-T7 (pTOL-PuxT7) cells with rifampin. Since T7 RNAP is not sensitive to this antibiotic, the upper TOL transcript (xylUW) can still be produced, while the $x y / X$ gene of the lower pathway should not. However, it is known that the diffusion rate of ribosomal proteins is faster $(11,12)$ and the chromosomal DNA of the nucleoid expands after treatment with this drug $(52,53)$. Finally, the dearth of ribosomes available for interacting with RNAs due to inhibition of 16s rRNA synthesis (54) may also ease diffusion of otherwise tethered transcripts. As a consequence, rifampin treatment elicits a major change in the partition of the different components of the gene expression flow and causes a less compact intracellular milieu.

After treatment of growing P. putida KT2440-T7 (pTOL-PuxT7) culture for $2 \mathrm{~h}$ with the drug and $m$-xylene vapors, the mRNAs were visualized with FISH as before. As expected, we could hardly detect any $x y I X$ mRNA signal (Fig. S6). In contrast, when cells were hybridized with the xylUW probe under the same conditions, red signals did appear (Fig. 7 and Fig. S7). Yet, inspection of individual bacteria revealed a considerable variability in the intensity of the signals and their intracellular distribution. Some cells had their whole contour nonuniformly filled with red color, while others showed a number of discrete red signals with lower intensity (Fig. 7 and Fig. S7). This outcome is not altogether unexpected, as the strong T7 promoter in the plasmid (55) drains cellular resources $(56,57)$ for the sake of transcription of the upper pathway, thereby causing noise. This effect can be exacerbated in a plasmid, as the loss of gyrase production with the drug and the ensuing accumulation of local supercoiling can lead to stochastic transcriptional bursts (58-60). In any case, we argue that the lack of distinct localization patterns in rifampin-treated cells reflects the diffusion of the TOL transcripts under these conditions. Moreover, some images showed enrichment of $x y / U W$ mRNAs in the cells' internal periphery, where the chromosome was otherwise highly compacted (Fig. S7, marked). In these cases, it looked like mRNA was unable to penetrate the denser DNA regions but could freely diffuse into the rest of the cytoplasmic space. Taken together, analysis of images shown in Fig. 7 and Fig. S7 indicated that the xyIUW transcript of rifampin-treated cells lost its restraint in discrete foci and 
could then freely circulate, as the cellular crowding had decreased upon antibiotic addition. In sum, the data suggest that under native conditions, $x y /$ mRNAs become localized away from the nucleoid because of their entrapment with the translational machinery and the physical forces that determine phase separation between the different components of the gene expression flow. As shown above, if such a separation is perturbed upon rifampin addition, $x y l$ transcripts can then circulate through the whole cytoplasmic interior.

In conclusion, this study shows that $x y /$ mRNAs are constrained within subcellular regions with limited mobility rather than being freely diffusible inside $P$. putida $\mathrm{mt}-2$ cells. Most $x y l$ transcripts were detected in the space peripheral to the nucleoid, i.e., in a subcellular domain with virtually no DNA but enriched in ribosomes (20). That TOL mRNAs were detected away from the genetic loci where they originated suggests that they can migrate to translational sites from the 3-D location in the cell where they were synthesized. Our data also show that physical forces and translation are crucial for bringing about this scenario, as it disappeared when in-house transcription was halted to reduce cellular crowding and ribosome engagement. This picture departs from the standard view of transcription-translation coupling, where RNAP and ribosomes get together in the so-called expressome complex $(45,46)$ which, obviously, must operate in close proximity to the nucleoid's DNA.

While transcript entrapment is a known mechanism of RNA control in eukaryotes (61-63), the phenomenon as such has not been documented in prokaryotes. However, should transcript diffusion away from the promoter and capture by ribosomes in a different cell location occur, confinement in given spots for translation could become visible. Some mRNAs can indeed travel throughout the interior of E. coli cells (64), and translation inhibition makes RNA remain closer to the nucleoid (47). This suggests that, at least in some cases, ribosomes in fact pull mRNA from the nucleoid toward the rest of the cytoplasm. The reality is that the interplay between the various components of the gene expression flow varies dramatically among bacterial types. In particular, the nucleocytoplasmic (NC) ratio changes greatly from one species to another, originating in cytoplasms with different biophysical properties (65) that affect ribosome mobility and localization. For instance, the high NC ratio of Caulobacter crescentus forces ribosomes toward mRNAs and their translating ribosomes to remain close to their genetic loci in the chromosomal DNA $(11,65,66)$. In contrast, the low NC ratio of $E$. coli allows segregation of ribosomes and mRNA away from their transcriptional sites. Pseudomonas spp. also have a low NC ratio (65) and the ribosomes are spatially segregated from the nucleoid (20). It is thus conceivable that TOL transcripts are not coupled to translation as they are produced, but instead move after complete transcription toward ribosome-rich cytoplasmic spots.

What could be the advantage of this setting of the $x y l$ gene expression flow in $P$. putida compared to an alternative subcellular architecture? This species has bona fide nusA and nusG homologues encoded in its genome. This indicates that transcription/ translation coupling can indeed occur $(45,46)$, although its global incidence compared to E. coli or Bacillus (19) is unknown. It may well happen that having movable $x y l$ mRNAs eases assembly of the biodegradative complex encoded by the TOL operons for degrading aromatic compounds. This is because the cognate catabolic enzymes, in particular those which are membrane bound (see above), could be synthesized at an optimal location site close to the site of action. Moreover, newly synthesized enzymes could be produced close to each other and enable metabolic channeling (67). Finally, while Rho and transcription/translation coupling helps avoiding RNAP collisions and Rloops-with the downside of polarity-some bacterial types could have solved the traffic jam problem by evolving a different type of termination (19). In fact, interruption of nontranslated transcripts may be detrimental for emergence of new catabolic operons; nonsense mutations in lead genes could prevent expression of the whole cluster and curb evolution of downstream ORFs. These are all of course hypothetical scenarios that deserve further studies. 


\section{MATERIALS AND METHODS}

Culture conditions. Unless otherwise indicated, $E$. coli and $P$. putida were routinely grown at $37^{\circ} \mathrm{C}$ and $30^{\circ} \mathrm{C}$, respectively, in Luria-Bertani (LB) or $\mathrm{M9}$ minimal medium $\left(6 \mathrm{~g}\right.$ liter $^{-1} \mathrm{Na}_{2} \mathrm{HPO}_{4}, 3 \mathrm{~g}$ liter $^{-1}$ $\mathrm{KH}_{2} \mathrm{PO}_{4}, 1.4 \mathrm{~g} \mathrm{liter}^{-1}\left[\mathrm{NH}_{4}\right]_{2} \mathrm{SO}_{4}, 0.5 \mathrm{~g} \mathrm{liter}^{-1} \mathrm{NaCl}, 0.2 \mathrm{~g} \mathrm{liter}^{-1} \mathrm{MgSO}_{4} \cdot 7 \mathrm{H}_{2} \mathrm{O}$ ) with $10 \mathrm{mM}$ succinate. Bacteria were cultured in 100-ml Erlenmeyer flasks with shaking at $170 \mathrm{rpm}$ with $20 \mathrm{ml}$ of the medium specified for the corresponding experiment. Whenever necessary, kanamycin ( $\left.\mathrm{Km}, 50 \mu \mathrm{g} \mathrm{ml}^{-1}\right)$, ampicillin $\left(A p, 150 \mu \mathrm{g} \mathrm{ml}^{-1}\right)$, gentamicin $\left(\mathrm{Gm}, 10 \mu \mathrm{g} \mathrm{ml}^{-1}\right)$, or chloramphenicol $\left(\mathrm{Cm}, 30 \mu \mathrm{g} \mathrm{ml}^{-1}\right)$ was added to cultures of bacterial cells for ensuring plasmid retention and maintenance of manipulated genotype. For the induction of TOL catabolic genes during RNA-FISH experiments, $P$. putida strains carrying the $x y l$ genes either in the pWWO plasmid or in the chromosome were cultured overnight in succinateamended M9 and then the bacterial cultures were 100-fold diluted in the same medium and grown until exponential phase (optical density at $600 \mathrm{~nm}\left[\mathrm{OD}_{600}\right]=0.3$ to 0.5 ). Samples were next either cultivated further without additional substrate or exposed to vapors of $m$-xylene (1:2 dilution in dibutylphthalate, which is a noneffector for TOL genes) in a flask for $2 \mathrm{~h}$. Additional tests were made by exposing the $P$. putida mt-2 strain to either vapors of volatile effectors (e.g., toluene or $o$-xylene) or soluble substrates such as benzoate $(5 \mathrm{mM})$ and 3-methylbenzoate $(3 \mathrm{MBz} ; 5 \mathrm{mM})$, as indicated. Transcription of the $x y /$ genes by endogenous RNA polymerase was halted by adding $200 \mu \mathrm{g} \mathrm{ml}^{-1}$ rifampin (Rif) to the growth medium of the cognate-sensitive strains.

Genetic constructs. The bacterial strains, plasmids, and primers used in this study are described in Tables S1 and S2 in the supplemental material. General methods for DNA manipulation followed standard protocols (68). Plasmid DNA was isolated with commercial Wizard Plus SV minipreps DNA purification kit (Promega) or the QIAprep Spin miniprep kit (Qiagen). To replace the Pu of the upper operon of the pWWO plasmid by the T7 phage promoter, we used the seamless allelic replacement method described in reference 69 . The delivery plasmid for executing the promoter replacement (pTOL-PuxT7) was built as follows. First, the upstream $\left(T S 1^{P u}, \sim 0.5 \mathrm{~kb}\right.$ ) and downstream (TS2 ${ }^{P u}, \sim 0.5 \mathrm{~kb}$ ) regions of the pWW0 plasmid around the $\mathrm{Pu}$ promoter were amplified with primer pairs PuxT7-TS1F/R and PuXT7TS2F/R, respectively (Table S2). Splice overlap extension PCR (SOEing PCR) was then used as explained in reference 69 to join the amplicon TS1 ${ }^{\mathrm{Pu}}$ and TS2 ${ }^{\mathrm{Pu}}$ (including $3^{\prime}$ - and $5^{\prime}$ - of the T7 promoter sequence with overhang complementarity) by using primer pairs PuXT7-TS1F and PuXT7-TS2R (Table S2). The resulting PCR product was cloned as EcoRI-BamHI segments in the pEMG vector, forming plasmid pEMG-PuxT7, which was kept in E. coli strain DH5 $\alpha \lambda$ pir. This plasmid was next delivered to the genome of $P$. putida mt-2 by triparental mating using the E. coli strain HB101 (pRK600) as helper strain $(70,71)$, and a cointegrate generated upon selection for $\mathrm{Km}^{\mathrm{R}}$. The pSW plasmid that expresses I-Scel endonuclease under the Pm promoter (72) was then introduced by electroporation into the pEMG-PuxT7-cointegrated strain and thus had resistance for both $\mathrm{Km}$ and $\mathrm{Ap}$. The clones were grown in LB medium with Ap $\left(500 \mu \mathrm{g} \mathrm{ml}^{-1}\right)$ and $3 \mathrm{MBz}(15 \mathrm{mM})$ to activate the $\mathrm{Pm}$ promoter, allowing I-Scel expression. The cells were then plated on LB agar and promoter replacement in the TOL plasmid was verified by testing the loss of the pEMG-PuxT7-encoded Km resistance gene. Sensitive clones were further confirmed with PCR with diagnostic T7F/PuXT7-TS2R primer pairs (Table S2). Finally, the resulting plasmid pTOL-PuxT7 was either maintained in the mt-2 strain or transferred into the KT2440-T7 strain by conjugation, as indicated.

To label pWWO with an array of tet operators, we inserted the cognate DNA sequence into a dispensable locus of the plasmid. To this end, a 570-bp PCR product was obtained using primer pairs 105F/ 105R (Table S2), which amplified a 5' segment of the orf105 gene of pWW0. The PCR product was then cloned as a HindIII-Notl segment of the pP30D-FRT-tetO vector (26), thus generating pP30D-FRT-tetOorf105. This plasmid was maintained in the E. coli CC118 strain and then passed to $P$. putida mt-2 strain to force recombination with pWWO. This originated strain P. putida mt-2 (pTOL-tetO), in which the TOL plasmid is tagged with the tet $O$ array borne by the integrated construct.

Fluorescent in situ hybridization. In order to visualize $x y /$ mRNAs, RNA-FISH was performed as described previously (11) with some modifications. Bacteria growing with or without aromatic effectors were fixed for $15 \mathrm{~min}$ at room temperature in $4 \%$ formaldehyde and $30 \mathrm{mM} \mathrm{NaHPO}$ ( $\mathrm{pH} 7.5)$, and then keeping the samples for $30 \mathrm{~min}$ on ice. Cells were spun down $3 \mathrm{~min}$ at 4,500 $\times g$ and the supernatant removed. Pellets were washed with diethyl pyrocarbonate (DEPC)-treated phosphate-buffered saline (PBS) and cells resuspended in $100 \mu \mathrm{l}$ of GTE buffer $(50 \mathrm{mM}$ glucose, $20 \mathrm{mM}$ Tris- $\mathrm{HCl}$ [pH 7.5], $10 \mathrm{mM}$ EDTA [pH 8]). Samples $(12 \mu \mathrm{l})$ were next mixed with $4 \mu \mathrm{l}$ of a solution of lysozyme and vanadyl ribonucleoside complex (VRC) such that the final concentrations of these reactions were $2.5 \mu \mathrm{g} \mathrm{ml}^{-1}$ and $2 \mathrm{mM}$, respectively. A 3- $\mu$ l aliquot of the resulting suspension was applied onto poly-L-lysine coated coverslips and stored at room temperature until dry. Coverslips were next immersed first in methanol $(10 \mathrm{~min})$ and then in acetone $(30 \mathrm{~s})$ at $-20^{\circ} \mathrm{C}$. After all liquid was removed, coverslips were kept at $37^{\circ} \mathrm{C}$ in $10 \%$ formamide solution, $2 \times$ saline-sodium citrate buffer (SSC) in DEPC-treated water, and $2 \mathrm{mM} \mathrm{VRC.}$ After $60 \mathrm{~min}$, samples were drained and $50 \mu \mathrm{l}$ of hybridization solution (10\% formamide, DEPC-treated $2 \times$ SSC, 10\% dextransulphate, 2 mM VRC, 40 U RNase inhibitor, and $250 \mathrm{nM} \mathrm{CAL} \mathrm{Fluor} \mathrm{Red} 610$ labeled FISH probes Stellaris, Biosearch Technologies; Table S3) was spotted onto the coverslips and incubated overnight at $42^{\circ} \mathrm{C}$ in a dark and humid chamber. Samples were then washed twice with $10 \%$ formamide in DEPC-treated $2 \times \mathrm{SSC}$ for $15 \mathrm{~min}$ at $37^{\circ} \mathrm{C}$, with DAPI $\left(2.5 \mu \mathrm{g} \mathrm{ml}^{-1}\right)$ added in the second washing step. After a brief rinse with PBS buffer, the coverslip was deposited on a slide glass treated with antifade reagent Prolong (Invitrogen) and sealed by clear nail polish. The specimen was visualized by fluorescence microscopy. To identify the intracellular position of the TOL plasmid carrying the tandem copies of the tet operators, DNA-FISH was performed with the 6-carboxyfluorescein (FAM)-labeled locked nucleic acid (LNA) tetO probe (5' 6-FAM-CTCTATCACTGATAGGGA; Bionova). The protocol was basically the same 
strategy as before with RNA-FISH, but hybridization was carried out first at $95^{\circ} \mathrm{C}$ for 2 min to denature DNA, and then at $42^{\circ} \mathrm{C}$ overnight in a dark and humid chamber. Fluorescent signals exposing $x y l$ mRNAs and tetO-tagged DNA were generated upon sequential application of RNA-FISH and DNA-FISH to the same samples.

Microscopy and image analysis. Microscopy was performed using an Olympus BX61 instrument equipped with a $100 \times$ phase contrast objective and a DP70 camera of the same brand. Signals for red-RNA, DAPI, and green-DNA were obtained using wide field excitation with the following filters; MWIY2, U-MNU2, and U-MNIBA2, respectively. Processing of multichannel images and measurement of relative fluorescent intensities were carried out using Fiji software. Analysis of fluorescent foci representing mRNA molecules in terms of their relative cellular positions with respect to the DAPI-stained nucleoid, was carried out with the CellShape package (23). To analyze overlaps between red and blue signals, the contour lines of both channels were calculated on RGB-TIF formatted images. For this, pixel values (red/blue channels) were extracted and the resulting values normalized within the interval $[0,1]$ in order to enable direct channel comparison regardless of any potential technical inconsistencies in measuring particular signals. This approach enabled estimation of contour lines with subpixel accuracy. The overlap values refer to the commonality between the contours for the red signals and the blue signals.

\section{SUPPLEMENTAL MATERIAL}

Supplemental material is available online only.

FIG S1, PDF file, $1 \mathrm{MB}$.

FIG S2, PDF file, $0.5 \mathrm{MB}$.

FIG S3, PDF file, 0.8 MB.

FIG S4, PDF file, 0.6 MB.

FIG S5, PDF file, 1.1 MB.

FIG S6, PDF file, 0.6 MB.

FIG S7, PDF file, $0.4 \mathrm{MB}$.

TABLE S1, PDF file, $0.1 \mathrm{MB}$.

TABLE S2, PDF file, $0.03 \mathrm{MB}$.

TABLE S3, PDF file, 0.04 MB.

\section{ACKNOWLEDGMENTS}

V.d.L. and J.K. designed the study and the experimental layout. J.K. did all the experiments with the assistance of A.G.-M., who developed and implemented the software for image analysis used throughout this work. J.K. and V.d.L. wrote the manuscript, with contributions from A.G.-M. to data analysis and interpretation of the results.

We thank Christine Jacobs-Wagner for sharing the protocol for FISH. Isabelle ValletGely and Karl-Erich Jaeger are gratefully acknowledged sharing of valuable materials, as is Belén Calles for insightful discussions.

This work was funded by the SETH (RTI2018-095584-B-C42 MINECO/FEDER) and SyCoLiM (ERA-COBIOTECH 2018 - PCI2019-111859-2) Projects of the Spanish Ministry of Science and Innovation, the MADONNA (H2020-FET-OPEN-RIA-2017-1-766975), BioRoboost (H2020-NMBP-BIO-CSA-2018-820699), SynBio4Flav (H2020-NMBP-TR-IND/ H2020-NMBP-BIO-2018-814650), and MIX-UP (MIX-UP H2020-BIO-CN-2019-870294) Contracts of the European Union, and the InGEMICS-CM (S2017/BMD-3691) Project of the Comunidad de Madrid-European Structural and Investment Funds (FSE, FECER). A.G.-M. was also supported by grants from Comunidad de Madrid (Atracción de Talento Program, grant 2019-T1/BIO-14053) and the Severo Ochoa Program for Centres of Excellence in R\&D from the Agencia Estatal de Investigación of Spain, grant SEV-2016-0672 (2017-2021).

We declare no conflicts of interest.

\section{REFERENCES}

1. Assinder SJ, Williams PA. 1990. The TOL plasmids: determinants of the catabolism of toluene and the xylenes. Adv Microb Physiol 31:1-69. https:// doi.org/10.1016/s0065-2911(08)60119-8.

2. Marques S, Manzanera M, Gonzalez-Perez MM, Gallegos MT, Ramos JL. 1999. The XylS-dependent Pm promoter is transcribed in vivo by RNA polymerase with sigma 32 or sigma 38 depending on the growth phase. Mol Microbiol 31:1105-1113. https://doi.org/10.1046/j.1365-2958.1999 .01249.x.
3. Worsey MJ, Williams PA. 1975. Metabolism of toluene and xylenes by Pseudomonas putida (arvilla) mt-2: evidence for a new function of the TOL plasmid. J Bacteriol 124:7-13. https://doi.org/10.1128/JB.124.1.7-13.1975.

4. Domínguez-Cuevas P, Marqués S. 2010. Transcriptional control of the TOL plasmid pathways. In Timmis KN (ed), Handbook of hydrocarbon and lipid microbiology. Springer, Berlin, Heidelberg, Germany. https://doi.org/10 .1007/978-3-540-77587-4_78.

5. Domínguez-Cuevas $P$, Marqués S. 2017. Current view of the mechanisms 
controlling the transcription of the TOL plasmid aromatic degradation pathways. In Rojo F (ed), Aerobic utilization of hydrocarbons, oils and lipids. Springer, Cham, Switzerland. https://doi.org/10.1007/978-3-319 -39782-5_29-1.

6. Rojo F, Alejandro Dinamarca M. 2004. Catabolite repression and physiological control. In Ramos JL (ed), Pseudomonas: virulence and gene regulation. Springer, Boston, MA. https://doi.org/10.1007/978-1-4419 -9084-6_13.

7. Koutinas M, Lam MC, Kiparissides A, Silva -Rocha R, Godinho M, Livingston AG, Pistikopoulos EN, de Lorenzo V, dos Santos VAM, Mantalaris A. 2010. The regulatory logic of $m$-xylene biodegradation by Pseudomonas putida mt-2 exposed by dynamic modelling of the principal node Ps/Pr of the TOL plasmid. Environ Microbiol 12:1705-1718. https://doi.org/10.1111/j.1462 $-2920.2010 .02245 . x$

8. Koutinas M, Kiparissides A, Silva-Rocha R, Lam M-C, dos Santos VAM, de Lorenzo V, Pistikopoulos EN, Mantalaris A. 2011. Linking genes to microbial growth kinetics: an integrated biochemical systems engineering approach. Metab Eng 13:401-413. https://doi.org/10.1016/j.ymben.2011 .02 .001 .

9. Silva-Rocha R, de Jong H, Tamames J, de Lorenzo V. 2011. The logic layout of the TOL network of Pseudomonas putida pWW0 plasmid stems from a metabolic amplifier motif (MAM) that optimizes biodegradation of $m$-xylene. BMC Syst Biol 5:191. https://doi.org/10.1186/1752-0509-5-191.

10. Silva-Rocha R, Tamames J, dos Santos VM, de Lorenzo V. 2011. The logicome of environmental bacteria: merging catabolic and regulatory events with Boolean formalisms. Environ Microbiol 13:2389-2402. https://doi.org/ 10.1111/j.1462-2920.2011.02455.x.

11. Montero Llopis P, Jackson AF, Sliusarenko O, Surovtsev I, Heinritz J, Emonet T, Jacobs-Wagner C. 2010. Spatial organization of the flow of genetic information in bacteria. Nature 466:77-81. https://doi.org/10 .1038/nature09152.

12. Sanamrad A, Persson F, Lundius EG, Fange D, Gynnå AH, Elf J. 2014. Single-particle tracking reveals that free ribosomal subunits are not excluded from the Escherichia coli nucleoid. Proc Natl Acad Sci U S A 111:11413-11418. https://doi.org/10.1073/pnas.1411558111.

13. Nevo-Dinur K, Nussbaum-Shochat A, Ben-Yehuda S, Amster-Choder O. 2011. Translation-independent localization of mRNA in E. coli. Science 331:1081-1084. https://doi.org/10.1126/science.1195691.

14. Kannaiah S, Livny J, Amster-Choder O. 2019. Spatiotemporal organization of the $E$. coli transcriptome: translation independence and engagement in regulation. Mol Cell 76:574-589. https://doi.org/10.1016/j.molcel.2019 .08.013.

15. Moffitt JR, Pandey S, Boettiger AN, Wang S, Zhuang X. 2016. Spatial organization shapes the turnover of a bacterial transcriptome. Elife 5:e13065. https://doi.org/10.7554/eLife.13065.

16. Libby EA, Roggiani M, Goulian M. 2012. Membrane protein expression triggers chromosomal locus repositioning in bacteria. Proc Natl Acad Sci U S A 109:7445-7450. https://doi.org/10.1073/pnas.1109479109.

17. Yang S, Kim S, Kim DK, Jeon An H, Bae Son J, Hedén Gynnå A, Ki Lee N. 2019. Transcription and translation contribute to gene locus relocation to the nucleoid periphery in E. coli. Nat Commun 10:5131. https://doi.org/10 .1038/s41467-019-13152-y.

18. Driessen AJ, Nouwen N. 2008. Protein translocation across the bacterial cytoplasmic membrane. Annu Rev Biochem 77:643-667. https://doi.org/ 10.1146/annurev.biochem.77.061606.160747.

19. Johnson GE, Lalanne J-B, Peters ML, Li G-W. 2020. Functionally uncoupled transcription-translation in Bacillus subtilis. Nature 585:124-128. https:// doi.org/10.1038/s41586-020-2638-5.

20. Kim J, Goni-Moreno A, Calles B, de Lorenzo V. 2019. Spatial organization of the gene expression hardware in Pseudomonas putida. Environ Microbiol 21:1645-1658. https://doi.org/10.1111/1462-2920.14544.

21. Kim J, Perez-Pantoja D, Silva-Rocha R, Oliveros JC, de Lorenzo V. 2016 High-resolution analysis of the $m$-xylene/toluene biodegradation subtranscriptome of Pseudomonas putida mt-2. Environ Microbiol 18:3327-3341. https://doi.org/10.1111/1462-2920.13054.

22. Abril MA, Michan C, Timmis KN, Ramos JL. 1989. Regulator and enzyme specificities of the TOL plasmid-encoded upper pathway for degradation of aromatic hydrocarbons and expansion of the substrate range of the pathway. J Bacteriol 171:6782-6790. https://doi.org/10.1128/jb.171.12 6782-6790.1989.

23. Goni-Moreno A, Kim J, de Lorenzo V. 2017. CellShape: a user-friendly image analysis tool for quantitative visualization of bacterial cell factories inside. Biotechnol J 12. https://doi.org/10.1002/biot.201600323.

24. Ramos JL, Duque E, Godoy P, Segura A. 1998. Efflux pumps involved in toluene tolerance in Pseudomonas putida DOT-T1E. J Bacteriol 180:3323-3329. https://doi.org/10.1128/JB.180.13.3323-3329.1998.

25. Bühler B, Witholt B, Hauer B, Schmid A. 2002. Characterization and application of xylene monooxygenase for multistep biocatalysis. Appl Environ Microbiol 68:560-568. https://doi.org/10.1128/aem.68.2.560-568.2002.

26. Vallet-Gely I, Boccard F. 2013. Chromosomal organization and segregation in Pseudomonas aeruginosa. PLoS Genet 9:e1003492. https://doi.org/ 10.1371/journal.pgen.1003492.

27. Greated A, Lambertsen L, Williams PA, Thomas CM. 2002. Complete sequence of the IncP-9 TOL plasmid pWW0 from Pseudomonas putida. Environ Microbiol 4:856-871. https://doi.org/10.1046/j.1462-2920.2002 .00305.x.

28. Goni-Moreno A, Benedetti I, Kim J, de Lorenzo V. 2017. Deconvolution of gene expression noise into spatial dynamics of transcription factorpromoter Interplay. ACS Synth Biol 6:1359-1369. https://doi.org/10 .1021/acssynbio.6b00397.

29. Schumacher MA. 2012. Bacterial plasmid partition machinery: a minimalist approach to survival. Curr Opin Struct Biol 22:72-79. https://doi.org/10 .1016/j.sbi.2011.11.001.

30. Gerdes K, Howard M, Szardenings F. 2010. Pushing and pulling in prokaryotic DNA segregation. Cell 141:927-942. https://doi.org/10.1016/j cell.2010.05.033.

31. Guynet C, de la Cruz F. 2011. Plasmid segregation without partition. Mob Genet Elements 1:236-241. https://doi.org/10.4161/mge.1.3.18229.

32. Marques S, Ramos JL, Timmis KN. 1993. Analysis of the mRNA structure of the Pseudomonas putida TOL meta fission pathway operon around the transcription initiation point, the $x y / T E$ and the $x y / F J$ regions. Biochim Biophys Acta 1216:227-236. https://doi.org/10.1016/0167-4781(93)90149-8.

33. Leija-Martinez N, Casas-Flores S, Cadena-Nava RD, Roca JA, MendezCabanas JA, Gomez E, Ruiz-Garcia J. 2014. The separation between the 5'-3' ends in long RNA molecules is short and nearly constant. Nucleic Acids Res 42:13963-13968. https://doi.org/10.1093/nar/gku1249.

34. Sinclair MI, Maxwell PC, Lyon BR, Holloway BW. 1986. Chromosomal location of TOL plasmid DNA in Pseudomonas putida. J Bacteriol 168:1302-1308. https://doi.org/10.1128/jb.168.3.1302-1308.1986.

35. Panke S, Sánchez-Romero JM, de Lorenzo V. 1998. Engineering of quasinatural Pseudomonas putida strains for toluene metabolism through an ortho-cleavage degradation pathway. Appl Environ Microbiol 64:748-751. https://doi.org/10.1128/AEM.64.2.748-751.1998.

36. Williams PA, Shaw LM, Pitt CW, Vrecl M. 1997. xylUW, two genes at the start of the upper pathway operon of TOL plasmid pWW0, appear to play no essential part in determining its catabolic phenotype. Microbiology 143:101-107. https://doi.org/10.1099/00221287-143-1-101.

37. Bryant JA, Sellars LE, Busby SJ, Lee DJ. 2014. Chromosome position effects on gene expression in Escherichia coli K-12. Nucleic Acids Res 42:11383-11392. https://doi.org/10.1093/nar/gku828.

38. Chaves JE, Wilton R, Gao Y, Munoz NM, Burnet MC, Schmitz Z, Rowan J, Burdick LH, Elmore J, Guss A, Close D, Magnuson JK, Burnum-Johnson KE, Michener JK. 2020. Evaluation of chromosomal insertion loci in the Pseudomonas putida KT2440 genome for predictable biosystems design. Metab Eng Commun 11:e00139. https://doi.org/10.1016/j.mec.2020.e00139.

39. Domröse A, Hage-Hülsmann J, Thies S, Weihmann R, Kruse L, Otto $M$, Wierckx N, Jaeger KE, Drepper T, Loeschcke A. 2019. Pseudomonas putida rDNA is a favored site for the expression of biosynthetic genes. Sci Rep 9:7028. https://doi.org/10.1038/s41598-019-43405-1.

40. Holtel A, Timmis KN, Ramos JL. 1992. Upstream binding sequences of the XyIR activator protein and integration host factor in the $x y / S$ gene promoter region of the Pseudomonas TOL plasmid. Nucleic Acids Res 20:1755-1762. https://doi.org/10.1093/nar/20.7.1755.

41. Perez-Martin J, De Lorenzo V. 1995. Integration host factor suppresses promiscuous activation of the sigma 54-dependent promoter $\mathrm{Pu}$ of $\mathrm{Pseu}$ domonas putida. Proc Natl Acad Sci U S A 92:7277-7281. https://doi.org/ 10.1073/pnas.92.16.7277

42. Troeschel SC, Thies S, Link O, Real Cl, Knops K, Wilhelm S, Rosenau F Jaeger KE. 2012. Novel broad host range shuttle vectors for expression in Escherichia coli, Bacillus subtilis and Pseudomonas putida. J Biotechnol 161:71-79. https://doi.org/10.1016/j.jbiotec.2012.02.020.

43. Marques S, Gallegos MT, Manzanera M, Holtel A, Timmis KN, Ramos JL. 1998. Activation and repression of transcription at the double tandem divergent promoters for the $x y / R$ and $x y / S$ genes of the TOL plasmid of Pseudomonas putida. J Bacteriol 180:2889-2894. https://doi.org/10.1128/JB .180.11.2889-2894.1998.

44. Gallegos MT, Marques S, Ramos JL. 1996. Expression of the TOL plasmid xylS gene in Pseudomonas putida occurs from s70-dependent promoter 
or from s70- and s54-dependent tandem promoters according to the compound used for growth. J Bacteriol 178:2356-2361. https://doi.org/ 10.1128/jb.178.8.2356-2361.1996.

45. Kohler R, Mooney RA, Mills DJ, Landick R, Cramer P. 2017. Architecture of a transcribing-translating expressome. Science 356:194-197. https://doi .org/10.1126/science.aal3059.

46. O'Reilly FJ, Xue L, Graziadei A, Sinn L, Lenz S, Tegunov D, Blötz C, Singh N, Hagen WJH, Cramer P, Stülke J, Mahamid J, Rappsilber J. 2020. In-cell architecture of an actively transcribing-translating expressome. Science 369:554-557. https://doi.org/10.1126/science.abb3758.

47. Sheng H, Stauffer WT, Hussein R, Lin C, Lim HN. 2017. Nucleoid and cytoplasmic localization of small RNAs in Escherichia coli. Nucleic Acids Res 45:2919-2934. https://doi.org/10.1093/nar/gkx023.

48. Minton AP. 2001. The influence of macromolecular crowding and macromolecular confinement on biochemical reactions in physiological media. J Biol Chem 276:10577-10580. https://doi.org/10.1074/jbc.R100005200.

49. Benny P, Raghunath M. 2017. Making microenvironments: a look into incorporating macromolecular crowding into in vitro experiments, to generate biomimetic microenvironments which are capable of directing cell function for tissue engineering applications. J Tissue Eng 8:2041731417730467. https://doi.org/10.1177/2041731417730467.

50. Trevors JT, van Elsas JD, Bej AK. 2013. The molecularly crowded cytoplasm of bacterial cells: dividing cells contrasted with viable but non-culturable (VBNC) bacterial cells. Curr Issues Mol Biol 15:1-6.

51. Parry BR, Surovtsev IV, Cabeen MT, O'Hern CS, Dufresne ER, JacobsWagner C. 2014. The bacterial cytoplasm has glass-like properties and is fluidized by metabolic activity. Cell 156:183-194. https://doi.org/10.1016/ j.cell.2013.11.028.

52. Bakshi S, Siryaporn A, Goulian M, Weisshaar JC. 2012. Superresolution imaging of ribosomes and RNA polymerase in live Escherichia coli cells. Mol Microbiol 85:21-38. https://doi.org/10.1111/j.1365-2958.2012.08081.x.

53. Chai Q, Singh B, Peisker K, Metzendorf N, Ge X, Dasgupta S, Sanyal S. 2014. Organization of ribosomes and nucleoids in Escherichia coli cells during growth and in quiescence. J Biol Chem 289:11342-11352. https:// doi.org/10.1074/jbc.M114.557348.

54. Bremer H, Berry L. 1971. Co-transcription of $16 \mathrm{~S}$ and $23 \mathrm{~S}$ ribosomal RNA in Escherichia coli. Nat New Biol 234:81-83. https://doi.org/10.1038/ newbio234081a0.

55. Marras SA, Gold B, Kramer FR, Smith I, Tyagi S. 2004. Real-time measurement of in vitro transcription. Nucleic Acids Res 32:e72. https://doi.org/10 .1093/nar/gnh068

56. Venturelli OS, Tei M, Bauer S, Chan LJG, Petzold CJ, Arkin AP. 2017. Programming mRNA decay to modulate synthetic circuit resource allocation. Nat Commun 8:15128. https://doi.org/10.1038/ncomms15128.

57. Kuderova A, Nanak E, Truksa M, Brzobohaty B. 1999. Use of rifampicin in T7 RNA polymerase-driven expression of a plant enzyme: rifampicin improves yield and assembly. Protein Expr Purif 16:405-409. https://doi .org/10.1006/prep.1999.1079.

58. Chong S, Chen C, Ge H, Xie XS. 2014. Mechanism of transcriptional bursting in bacteria. Cell 158:314-326. https://doi.org/10.1016/j.cell.2014.05 .038 .
59. Yeung E, Dy AJ, Martin KB, Ng AH, Del Vecchio D, Beck JL, Collins JJ, Murray RM. 2017. Biophysical constraints arising from compositional context in synthetic gene networks. Cell Syst 5:11-24. https://doi.org/10 .1016/j.cels.2017.06.001.

60. Kim S, Beltran B, Irnov I, Jacobs-Wagner C. 2019. Long-distance cooperative and antagonistic RNA polymerase dynamics via DNA supercoiling. Cell 179:106-119. https://doi.org/10.1016/j.cell.2019.08.033.

61. Kloc M, Zearfoss NR, Etkin LD. 2002. Mechanisms of subcellular mRNA localization. Cell 108:533-544. https://doi.org/10.1016/s0092-8674(02) 00651-7.

62. Forrest KM, Gavis ER. 2003. Live imaging of endogenous RNA reveals a diffusion and entrapment mechanism for nanos mRNA localization in Drosophila. Curr Biol 13:1159-1168. https://doi.org/10.1016/s0960-9822(03) 00451-2.

63. Shav-Tal Y, Darzacq X, Shenoy SM, Fusco D, Janicki SM, Spector DL, Singer RH. 2004. Dynamics of single mRNPs in nuclei of living cells. Science 304:1797-1800. https://doi.org/10.1126/science.1099754.

64. Golding I, Cox EC. 2004. RNA dynamics in live Escherichia coli cells. Proc Natl Acad Sci U S A 101:11310-11315. https://doi.org/10.1073/pnas .0404443101 .

65. Gray WT, Govers SK, Xiang Y, Parry BR, Campos M, Kim S, Jacobs-Wagner C. 2019. Nucleoid size scaling and intracellular organization of translation across bacteria. Cell 177:1632-1648. https://doi.org/10.1016/j.cell.2019.05 .017.

66. Campos M, Jacobs-Wagner C. 2013. Cellular organization of the transfer of genetic information. Curr Opin Microbiol 16:171-176. https://doi.org/ 10.1016/j.mib.2013.01.007.

67. Castellana M, Wilson MZ, Xu Y, Joshi P, Cristea IM, Rabinowitz JD, Gitai Z, Wingreen NS. 2014. Enzyme clustering accelerates processing of intermediates through metabolic channeling. Nat Biotechnol 32:1011-1018. https://doi.org/10.1038/nbt.3018.

68. Sambrook J, Russell D. 2001. Molecular cloning: a laboratory manual. Cold Spring Harbor Laboratory Press, Cold Spring Harbor, NY.

69. Martinez-Garcia E, de Lorenzo V. 2011. Engineering multiple genomic deletions in Gram-negative bacteria: analysis of the multi-resistant antibiotic profile of Pseudomonas putida KT2440. Environ Microbiol 13:2702-2716. https://doi.org/10.1111/j.1462-2920.2011.02538.x.

70. de Lorenzo V, Timmis KN. 1994. Analysis and construction of stable phenotypes in Gram-negative bacteria with Tn5- and Tn10-derived minitransposons. Methods Enzymol 235:386-405. https://doi.org/10.1016/ 0076-6879(94)35157-0.

71. Kessler B, de Lorenzo V, Timmis KN. 1992. A general system to integrate lac Z fusions into the chromosomes of Gram-negative eubacteria: regulation of the $\mathrm{Pm}$ promoter of the TOL plasmid studied with all controlling elements in monocopy. Mol Gen Genet 233:293-301. https://doi.org/10 .1007/BF00587591.

72. Wong SM, Mekalanos JJ. 2000. Genetic footprinting with mariner-based transposition in Pseudomonas aeruginosa. Proc Natl Acad Sci U S A 97:10191-11016. https://doi.org/10.1073/pnas.97.18.10191. 